\title{
Favoring argumentative disciplinary discussions in the classroom. A study of teacher's questions at undergraduate and graduate level
}

\begin{abstract}
This study sets out to examine the teacher's questions to their students during argumentative disciplinary discussions in the classroom, i.e., task-related argumentative discussions concerning the discipline taught in the course, with the aim to compare the types of questions used at undergraduate and graduate level. The data corpus is constituted by 16 video-recorded lessons (about $24 \mathrm{~h}$ of video) of two courses - one at undergraduate level and one at graduate level - in Developmental Psychology. The two courses were selected according to the following criteria: i) similar number of students, ii) similar disciplinary domain, iii) both courses are taught by the same teacher in English language. The findings of this study show that at the undergraduate level, the teacher asks broad questions to her students with the aim to favor a large discussion with and among students around general topics relating to Developmental Psychology. At the graduate level the teacher asks specific questions that refer to scientific theories or to certain aspects of a theory in the field of Developmental Psychology. Moreover, at the graduate level both types of teacher's questions are often followed by a further why-questions asked to the students.
\end{abstract}

Keywords: Argumentation; Higher Education; Qualitative Research; Student-Teacher Interaction; Teaching Strategies 


\section{Introduction}

The research on argumentation in science education has been intensified considerably, attracting growing attention "as a linguistic, logical, dialogical, and psychological process that sustains or provokes reasoning and learning" (Muller Mirza \& Perret-Clermont, 2009, p.1). Not by chance, an explicit goal of the current reform movement in science education in EU is to promote the development of the argumentative skills of students through teaching practices that encourage and facilitate argumentative debates in the classroom.

Since argumentation and discourse are central to the work of scientists, their role in science teacher education is relevant since teachers need to emulate and facilitate both in their classrooms. In addition, both contribute to a pedagogically relevant sociocultural framework for learning and can precipitate the active constructivism which can help students take ownership over their learning. (Eurydice ${ }^{1}, 2011$, p.105)

However, while other theoretical frameworks aimed at favoring the dialogic interaction in the classroom have already demonstrated their effectiveness in order to improve the quality of teaching in classroom and the learning of students, e.g., the dialogic teaching (Mortimer \& Scott, 2003), hitherto the practice of argumentation rather than a precise teaching strategy has been mostly used as a framework for discourse analysis to assess, for example, cognitive and learning competencies of students. In the learning contexts, argumentation is neither a heated exchange between rivals that results in winners and losers nor it can be merely used as a framework for discourse analysis of the verbal interactions occurring in the classroom (Duschl et al., 2007; Kelly \& Chen, 1999; Sandoval $\&$ Reiser, 2004). Rather, the practice of argumentation should be intended as an instrument enabling students to engage in knowledge construction.

From primary school to the academic context students encounter issues and positions that need to be developed, defended or evaluated (Buty \& Plantin, 2008; Driver et al., 1994; Erduran \& Jiménez-Aleixandre, 2007; Kuhn, 1993; Newton et al., 1999; Schwarz, 2009). Shifting the focus from the rote memorization of notions and theories to practices in which students construct and justify scientific claims should be, therefore, one of the main goals underlying the teaching strategies of every learning institution. Accordingly, empirical research that examines whether and how the practice of argumentation is promoted in the classroom has to become the area of major concern for science education research.

The present study intends to provide a contribution to the line of research on argumentation in the learning contexts. It specifically centers on the learning context of higher education and sets out to examine the teacher's questions to their students to favor the beginning of argumentative disciplinary discussions in the classroom, i.e., task-related discussions concerning the discipline taught in the course. In line with other scholars (Kuhn, 1991; Voss \& Van Dyke, 2001), I refer to an individual argument as a product and to the argumentative discussion as a process, the latter being implicit in the former. That being said, it is not a goal of the present study to make an assessment of the arguments advanced by students in response to the teacher's questions, i.e. deciding whether or not a certain argument respects logical criteria. Rather, the goal is to compare the types of questions asked by the teacher to undergraduate and graduate students during argumentative disciplinary discussions in the classroom.

The data corpus on which the present study is based is composed of sixteen video-recorded separate lessons of one Bachelor's degree and one Master's degree course. In order to focus on the 
teacher's questions, the object of investigation will be the argumentative discussions between students and teacher, as well as among students, occurring during their ordinary lessons, rather than an ad hoc setting created to favor the beginning of argumentative discussions. The analytical approach for the identification of the argumentative discussions is the pragma-dialectical ideal model of a critical discussion (van Eemeren \& Grootendorst 2004). This model proposes an ideal definition of argumentation developed according to the standard of reasonableness: an argumentative discussion starts when the speaker advances his/her standpoint, and the listener casts doubts upon it, or directly attacks the standpoint. Accordingly, confrontation, in which disagreement regarding a certain standpoint is externalized in a discursive exchange or anticipated by the speaker, is a necessary condition for an argumentative discussion to occur. This model particularly fits this study, and more generally, the study of argumentative interactions occurring in ordinary contexts, because it provides specific criteria in order to select and identify the argumentative discussions.

The present paper is structured as follows: in Section 2, a concise review of the most relevant literature on argumentation in learning contexts of higher education will be presented. In Section 3, the methodology on which the present study is based will be described. The results of the analysis are discussed in Section 4, followed by the Section 5, which summarizes the main findings and comments on their limitations and strengths.

\section{Argumentation Studies In Learning Contexts Of Higher Education}

Over the past two decades, the studies devoted to investigating the argumentative practices in the learning contexts have been in large part focused on primary and middle school level (Baker, 2002; Duschl \& Osborne, 2002; Jackson, 2002; Jiménez-Aleixandre, 2007; Nestlog, 2009; Osborne et al., 2001; Sadler, 2006; Schwarz \& Glassner, 2003). The attention of many scholars has been particularly directed to establish which criteria must be included in assessing the argumentative skills of pupils and students (Anderson et al., 1997; Garcia-Mila \& Andersen, 2007; Muller Mirza et al., 2009; Pontecorvo \& Girardet, 1993) and how to further improve these skills (Dolz, 1996; Kuhn \& Udell, 2003; Nussbaum \& Schraw, 2007; Schwarz \& Linchevski, 2007; Stein \& Miller, 1993; Zohar \& Nemet, 2002). Although they are fewer in number, the studies focusing on the argumentative practices in the learning contexts of higher education too have brought to light relevant insights from an educational and argumentative perspective. In particular, two main lines of research have to be distinguished within these studies.

The first line of research aims to examine how the argumentative practices might promote students' learning in the classroom. For instance, Chin and Osborne (2010) showed that favoring argument discussions in the classroom might enhances students' motivation, whilst Schwarz and colleagues (2000) showed that the practice of argumentation among students helps them to detect and resolve errors. A series of studies have also indicated that argumentative interaction in the classroom is important since it involves extra thinking, the need to "dig deeper" into the question being addressed (Baker, 2009; Hatano \& Inagaki, 2003; McNeill \& Krajcik, 2009; Schwarz et al., 2003). In the same vein, other studies have also shown that engagement in argumentative interactions in the classroom enhances students' knowledge by promoting conceptual change (Nussbaum \& Sinatra, 2003; Wiley \& Voss, 1999), and that the engagement in argumentative small- or large-group discussions improves conceptual understanding (Alexopoulou \& Driver, 1996; Andrews, 2009; Mason, 1996, 2001). Argumentative debates have been also the core of a 
previous research project centered on the learning context of higher education: the SCOPE (Science Controversies Online: Partnerships and Education) project (for more information, see Bell \& Linn, 2000).

The second line of research aims at investigating how students' argumentative competencies can favor or disfavor the learning process. In this respect, the role of argumentation in the academic context is currently stressed by a growing literature that emphasizes the problem of constructing students' knowledge taking into account their previous beliefs (Macagno \& Konstantinidou, 2013; Sampson \& Clark, 2008; Driver et al., 2000; Jiménez-Aleixandre et al., 2000; Kelly \& Takao, 2002). Osborne (2005) has shown that students support predictive claims or justify their points of view by advancing arguments that are borne out by explicit or implicit premises, or that can be more or less complete. Another interesting aspect is the important role played by grade level in favoring the production of arguments by students. The influence of this factor has been explained in terms of knowledge about the topic under consideration. It has been documented that previous knowledge in the domain is a significant predictor of comprehension of the arguments advanced within a scientific text (e.g., Alexander et al., 1994). Moreover, Means and Voss (1996) have shown that older students have greater knowledge, and that knowledge of the topic positively affects the number of arguments generated.

Overall, the studies focusing on the learning contexts of higher education have clearly indicated that the practice of argumentation in the classroom enables students to engage in knowledge construction and, consequently, to enhance their learning. However, in contrast to argumentation in informal settings such as family mealtimes (Bova \& Arcidiacono 2014, 2015), argumentation in the learning contexts rarely occurs spontaneously. The argumentative disciplinary discussions in the classroom are to be explicitly promoted through teaching strategies that support student-to-student and student-to-teacher interactions (Hogan \& Maglienti, 2001; Simon et al., 2006, Zohar \& Nemet, 2002). Accordingly, the role of the teacher is crucial to foster students' engagement in argumentation.

The present study intends to provide a further contribution to the recent literature on argumentation in the learning contexts of higher education. The purpose of this paper is to investigate the teacher's questions to their students to favor the beginning of argumentative disciplinary discussions in the classroom, i.e., task-related argumentative discussions concerning the discipline taught in the course, with the aim to compare the types of questions used at undergraduate and graduate level.

\section{Methodology}

\subsection{Data Corpus}

The data corpus is composed of sixteen video-recorded separate lessons (constituting about 24 hours of video data ) of one Bachelor's degree (sub-corpus 1) and one Master's degree course (subcorpus 2). The length of each recording varies from 84 to 98 minutes. The two courses have been selected according to the following criteria: i) similar number of students (about 15 students); ii) similar disciplinary domain (both courses considered handle are in the area of developmental psychology); iii) both courses are taught by the same teacher in English language.

Sub-corpus 1 consists of 8 video-recorded lessons of the third year elective course "Adolescent Development: Research, Policy, and Practice" of the Bachelor's degree at the 
University College of Utrecht (UCU) ${ }^{2}$. The sub-corpus 1 is constituted by 14 students, 4 boys and 10 girls. All the students at the time of data collection were in their early $20 \mathrm{~s}(\mathrm{M}=21.80 ; \mathrm{SD}=$ 1.80). There was no significance difference of age between boys $(M=21.89 ; \mathrm{SD}=2.66)$ and girls $(\mathrm{M}=21.74 ; \mathrm{SD}=1.20)$. As for the student's nationality, this class could be defined as very international. The students, in fact, came from 8 different countries: 7 from Netherlands, 1 from Finland, 1 from Mexico, 1 from Scotland, 1 from Germany, 1 from United States, 1 from Israel, and 1 from Austria.

Sub-corpus 2 consists of 8 video-recorded lessons of the first year elective course "Human development and developmental psychopathology" of the Master's degree program Development and Socialization in Childhood and Adolescence (DASCA) at the Utrecht University (UU) ${ }^{3}$. The sub-corpus 2 is constituted by 16 students, who were all girls. Most of the students at the time of data collection were in their early 20s $(\mathrm{M}=23.00 ; \mathrm{SD}=1.60)$. As for the student's nationality, the sub-corpus 2 was in large part composed from Dutch students $(\mathrm{N}=12)$, and from only 4 students coming from abroad: 1 from Serbia, 1 from United States, 1 from France, and 1 from Spain.

\subsection{Students' level of knowledge of the discipline}

Before starting the first lesson of the course (December 2013), both undergraduate and graduate students were asked by their teacher (i) to rate in a scale from 1 (none) to 9 (excellent) their own ability to communicate in English language, (ii) if they had already took an academic course in Developmental Psychology, and (iii) to rate in a scale from 1 (none) to 9 (excellent) the level of their previous knowledge in Developmental Psychology, i.e., before taking the course (see Appendix A). As for the ability to communicate in English language, in a scale from 1 to 9 the average score of the undergraduate students, according to their own perception, was $\mathrm{M}=8.28$, whilst the average score of the graduate students was slightly lower $M=7.56$. The most part of the students did already take an academic course in Developmental Psychology, both undergraduate (Yes $\mathrm{N}=12$; No $\mathrm{N}=2$ ) and graduate level (Yes $\mathrm{N}=15$; No $\mathrm{N}=1$ ). In regard to the level of their previous knowledge of the discipline taught in the course, in a scale from 1 to 9 the average score of the undergraduate students, according to their own perception, was slightly lower $(\mathrm{M}=6.35)$ than graduate students $(\mathrm{M}=7.25)$.

Detailed information on the information obtained from the questionnaire are presented below, in Table 1:

\section{INSERT HERE TABLE 1}

\subsection{Data collection and transcription procedures}

For each course, eight lessons over a twelve-week period during the Fall 2013 semester were videotaped. Each lesson lasted about 1 hour 15 minutes. The lessons were typical of the degree courses as a whole since the students were not asked to read materials before the lessons. Most of the time the teacher used a direct teaching method. However, sometimes the students were asked to work cooperatively together using student-centered and inquiry-based learning.

In order to capture the interactions between students and teacher and among students, the whole classroom was videotaped by placing one camera in a back-side corner of the classroom. 
Each lesson was recorded in its entirety. To minimize researcher interference, the researcher was not present into the classroom during the lessons, since he fixed the cameras before starting the lesson and returned to the classroom only once that the students have left the classroom. This means that lessons are documented as they naturally happen, without the researcher imposing tasks or topics, orchestrating the spatial positioning of participants, or affecting the setting of the interaction.

All lessons have been transcribed in their totality with the CHILDES standard transcription system $^{4}$ (CHAT) (MacWhinney, 2000), with some modifications introduced to enhance readability (see Appendix B), and revised by two researchers until a high level of consent has been reached. The level of agreement between the two researchers, as measured by Cronbach's alpha, was very high (.83). In all examples, discursive turns are numbered progressively within the sequence, and participants are identified by role for the teacher (e.g., TEACH) and by role, number, and gender for student (e.g., STU1M, STU2F, STU3F, etc.). In order to ensure the anonymity of students, their names in the paper are pseudonyms.

\subsection{Ethical Issues}

All participants were approached by means of an information sheet outlining in clear language the general purpose of the study and providing information about how the video data would be used. Consent letters have been written in accordance with Dutch Association of Psychologists (NIP) and American Psychological Association (APA) guidelines, specifically, the format outlined in the fifth edition of the Publication Manual of the American Psychological Association (APA, 2009). In line with the ethical framework guiding the research, the students were assured that their anonymity would be maintained at all stages of the study. Transcriptions and video-recorded material have been treated in the strictest confidence and seen only by researchers.

\subsection{Analytical Approach}

The analytical approach adopted for the analysis is the pragma-dialectical ideal model of a critical discussion (van Eemeren \& Grootendorst, 2004). This approach considers that argumentative speech acts are not performed in a social vacuum, but between two or more parties who are having a disagreement and interact with each other in an attempt to resolve this disagreement. The model of a critical discussion spells out four stages that are necessary for a dialectical resolution of differences of opinion (see van Eemeren \& Grootendorst, 2004, pp. 60-61):

Confrontation stage. At the confrontation stage, it is established that there is a dispute. A standpoint ${ }^{5}$ is advanced and questioned.

- Opening stage. At the opening stage, the decision is made to attempt to resolve the dispute by means of a regulated argumentative discussion. One party takes the role of protagonist, which means that he is prepared to defend his standpoint by means of argumentation; the other party takes the role of antagonist, which means that he is prepared to challenge the protagonist systematically to defend his standpoint.

Argumentation stage. At the argumentation stage, the protagonist defends his standpoint and the antagonist elicits further argumentation from him if he has further doubts. 
- $\quad$ Concluding stage. At the concluding stage, it is established whether the dispute has been resolved on account of the standpoint or the doubt concerning the standpoint having been retracted.

In the present study, the ideal model of a critical discussion is assumed as a grid for the analysis since it provides the criteria for the selection of the argumentative discussions.

\subsection{Selection of Argumentative Discussions}

For the present study, only the discussions that fulfill two of the following three criteria, one between i. $a$ and $i . b$ and always ii., were selected for analysis:

i.a at least one standpoint concerning an issue related to the discipline taught in the course put forth by one or more students is questioned - either by means of a clear disagreement or by means of a doubt - by the teacher or by (at least) one classmate, e.g. STU1F: I think that Piaget's notion that children's development must necessarily precede their learning is wrong - STU2F: No, I think that Piaget was right.

i.b at least one standpoint concerning an issue related to the discipline taught in the course put forth by the teacher is questioned - either by means of a clear disagreement or by means of a doubt - by one or more students, e.g. TEACH: During this phase ((adolescence)) they ((adolescents)) have to decide their goals and values for their future - STU6M: Some adolescents decide not to choose though.

ii. at least one student advances at least one argument either in favor of or against the standpoint being questioned, e.g. STU1: Some adolescents decide not to choose though, according to Marcia it's the identity diffusion, they are not ready to take these decisions.

\subsection{Identification of the types of questions}

All the transcriptions of the lessons were read independently by two coders who then met to compare their analysis and resolve differences in interpretation. Two different aspects of the analysis were compared to check inter-rater reliability. First, whether a standpoint concerning an issue related to the discipline taught in the course put forth by one or more students or by the teacher was questioned - either by means of a clear disagreement or by means of a doubt - was investigated; the percentage of agreement between the two raters, as measured by Cronbach's alpha, was .95 . Second, the two raters read the transcript independently to identify the questions that were asked by the teacher to their students; the percentage of agreement between the two raters, as measured by Cronbach's alpha, was .92 .

Once identified, the questions asked by the teacher were distinguished according to the following two criteria:

- the question refers to broad topics in the field of Developmental Psychology (hereafter, BROAD QUESTION), e.g. What are the main reasons leading to episodes of bullying among adolescents? 
- the question refers to a specific theory or to a certain aspect of a theory in the field of Developmental Psychology (hereafter, SPECIFIC QUESTION), e.g. Which developmental processes can be studied by each of the seven models described by Graber and BrooksGunn and how?

\section{Results}

The entire corpus was composed of $\mathrm{N}=94$ argumentative disciplinary discussions, $\mathrm{N}=59$ at graduate level and $\mathrm{N}=35$ at undergraduate level. In those cases in which the teacher repeated the question using the same or slightly different language, that question did count as two separate questions. The total number of questions asked by the teacher to their students during the argumentative disciplinary discussions in the classroom was $\mathrm{N}=272, \mathrm{~N}=161$ at graduate level and $\mathrm{N}=121$ at undergraduate level. Detailed information on the results of the analyses of the types of questions asked by the teacher to their students is presented below (Table 2). Excerpts of talk-ininteraction representative of the results obtained from the larger set of analyses conducted on the whole corpus of teacher's questions will follow in the next sections.

\section{INSERT HERE TABLE 2}

\subsection{Teacher's questions at undergraduate level}

The analysis of the questions asked by the teacher to their undergraduate students involved the $\mathrm{N}=$ 35 argumentative discussions arisen around an issue related to the discipline taught in the course for a total number of $\mathrm{N}=121$ questions. The findings show that in large part the teacher asked BROAD QUESTIONS to her students $(\mathrm{N}=87 ; 72 \%)$. The following excerpt presents a clear illustration of the use of this type of question by the teacher.

\section{Excerpt 1}

Lesson 3. Min. 38:12. Participants: teacher (TEACH), students (STU2F; STU14M). All the tables are placed in a horseshoe shape with the students facing the teacher. All students are seated at their own table. STU2F sits on the right hand side of TEACH, whilst STU14M is seated facing TEACH.

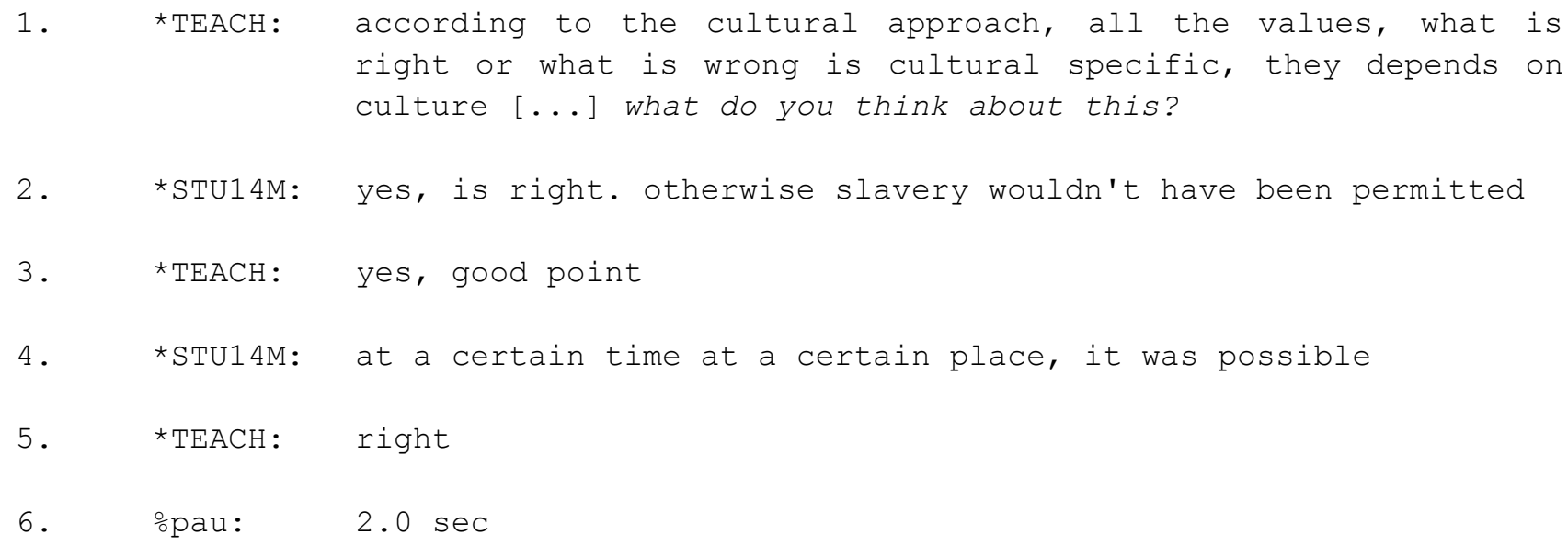




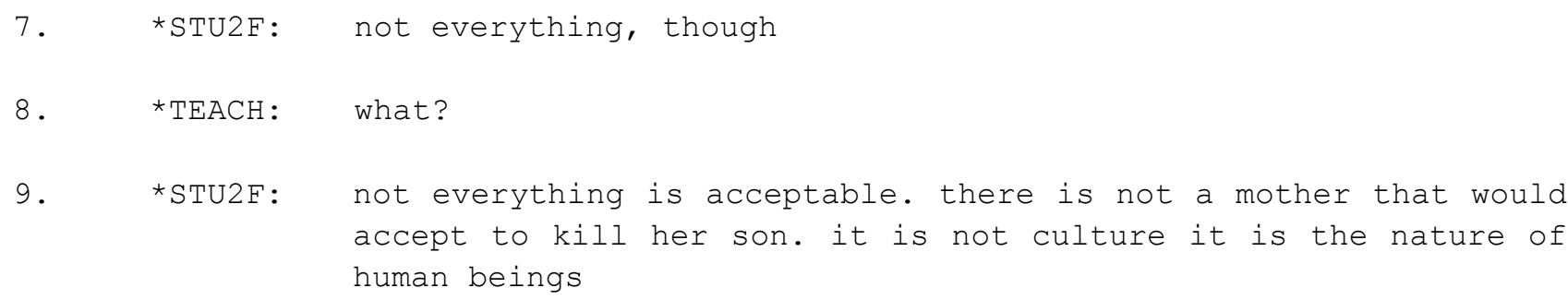

[...]

In this example we can observe how the teacher asked a BROAD QUESTION (line 1, in Italic in the excerpt: "what do you think about this?") to her students in order to favor the beginning of a discussions among them around a general topic related to Developmental Psychology, i.e., the cultural approach and its implications. With this question, the teacher favors a large discussion in the classroom since the students are not requested to have a detailed knowledge of the cultural approach to participate in this discussion. Not by chance, subsequently we can see that the students actually engage in an argumentative discussion. The student STU2F put forth an argument (line 9) to oppose another argument (line 2 and line 4) previously advanced by one of her classmate (STU14M).

In the corpus, the teacher asked only in few occasions SPECIFIC QUESTIONS to her undergraduate students $(\mathrm{N}=34 ; 28 \%)$. These questions were typically asked by the teacher when the argumentative discussion was started and the students had already advanced their opposite standpoints. The goal of these questions was not to favor the beginning of a new discussion among students but rather the continuation of a pre-existing discussion. A clear example of the use of this type of question by the teacher is illustrated in the following excerpt.

\section{Excerpt 2}

Lesson 4. Min. 59:30. Participants: teacher (TEACH), student (STU6M). All the tables are placed in a horseshoe shape with the students facing the teacher. All students are seated at their own table. STU6M sits on the right hand side of TEACH.

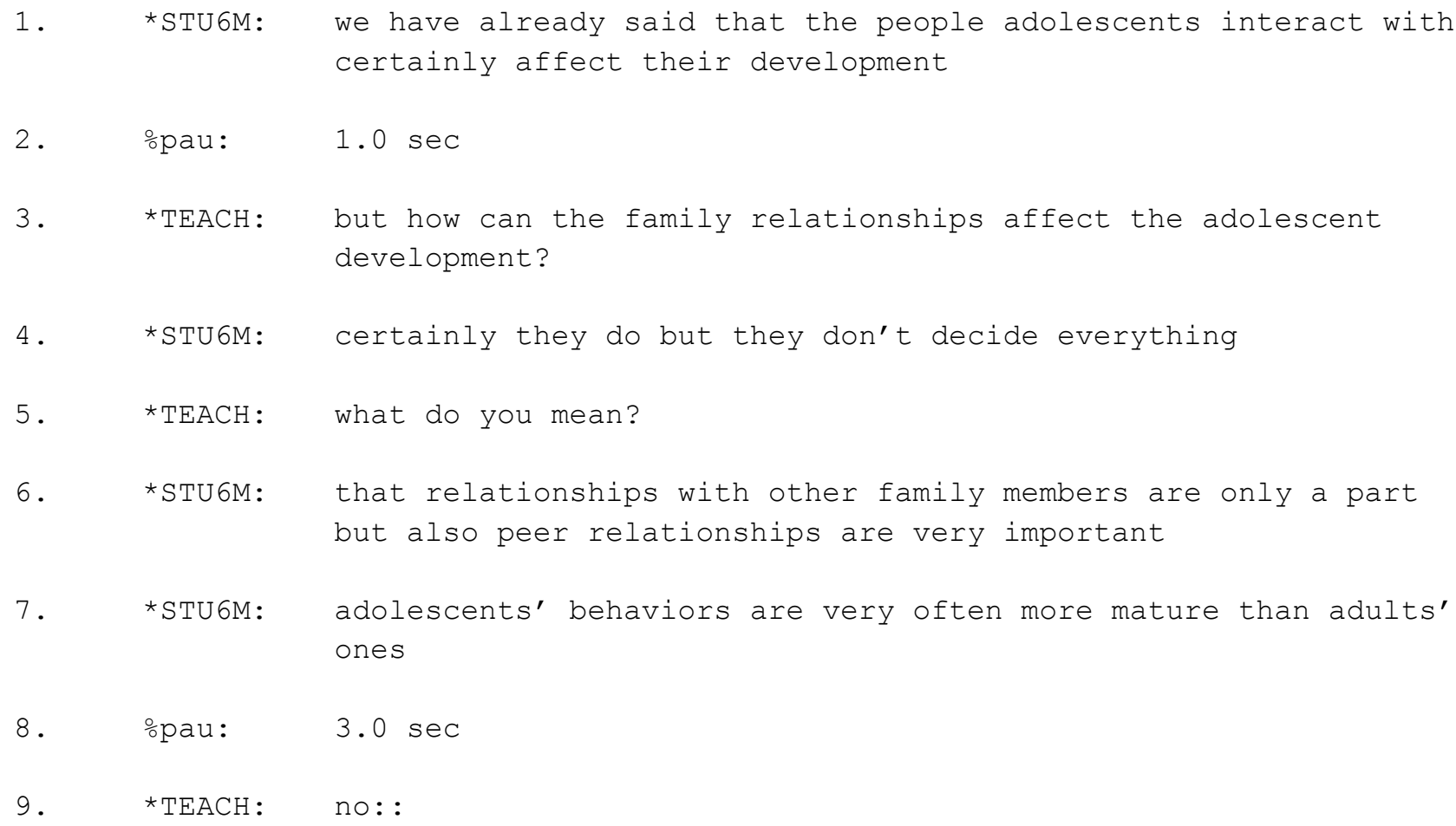


10

11

12.

13.

*TEACH : oh. yes professor ((laughing))

adolescence typically have more dangerous behaviors than adults

but Kohlberg said that adolescents can normally respect

authority ad rules, and that's pretty good

you just mentioned Kohlberg's theory. which stage of Kohlberg's theory describes this level of development?

In example 2, we can observe that the teacher and the students are discussing about a wellknown topic in the of field of Developmental Psychology, namely, the moral development in adolescence. During the first phase of the discussion, the teacher asks a BROAD QUESTION to her students (line 3). This question aims to favor the beginning of a discussion in the classroom relating to the effect of the family relationships on the adolescent development. The teacher does not make any reference to specific psychological theories that treat this topic. Rather, she asks their students to advance their own point of view about the topic object of the discussion. The effect produced by the teacher's question is that students actually start a discussion with the teacher about the effect of the family relationships on the adolescent development. Interestingly, only afterwards one of the students (STUD6M) advances an argument based on a specific psychological theory, i.e., Kohlberg's theory of moral development (Kohlberg, 1984) (line 12), the teacher asks a SPECIFIC QUESTION based on the same theory mentioned by her student (line 13, in Italic in the excerpt). This discussion will continue for several turns, involving other students as well.

\subsection{Teacher's questions at graduate level}

The analysis of the questions asked by the teacher to their graduate students involved the $\mathrm{N}=59$ argumentative discussions arisen around an issue related to the discipline taught in the course for a total number of $\mathrm{N}=161$ questions. Differently from what was observed for undergraduate students, the findings indicate that more than half of the times the teacher asked SPECIFIC QUESTIONS to her students $(\mathrm{N}=96 ; 60 \%)$. The following excerpt presents a clear illustration of the use of this type of question by the teacher.

\section{Excerpt 3}

Lesson 6. Min. 32:15. Participants: teacher (TEACH), student (STU7F; STU14F). All the tables are placed in a round shape, and all students are seated at their own table. The teacher is seated together with the students. STU7F and STU14F sit on the left hand side of TEACH.

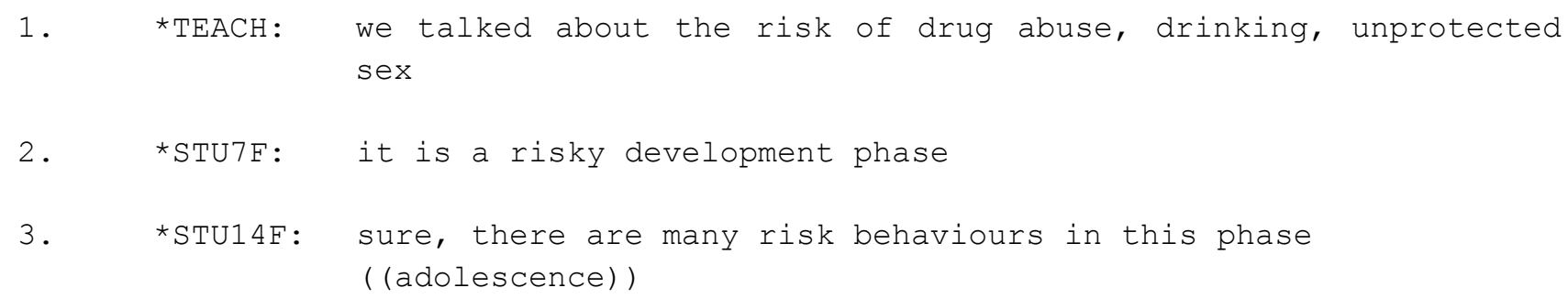


4.

5

6.

7. $\quad$ TEACH :

8. $\quad *$ STU14F :

what are the most important processes that according to Steinberg and Morris explain the fact that many risk behaviors tend to peak in adolescence?

they say that most teens know plenty about the dangers of risk-taking behaviors like drinking, smoking, and taking drugs, but they ignore on purpose what they have learned

this is not true, it is the influence of peers. Steinberg and Morris said that the presence of peers increased risk taking by $50 \%$ in adolescence

why do their presence ( (of peers) increase risk taking in adolescence?

when they are not around peers, adolescents are much better at controlling impulsive or risky behaviors

$[\ldots]$

In example 3, the topic of the discussion between teacher and students is "risk behaviours in adolescence". In line 3, (in Italic in the excerpt) the teacher asks a SPECIFIC QUESTION to her students related to one of the best-known grand theories of adolescent development, namely, the theory of adolescent development and psychological functioning proposed by Laurence Steinberg and Amanda S. Morris (Steinberg \& Morris, 2001). In this case, the teacher's question favors the beginning of an argumentative discussion initially between two students who clearly have to different opinions, STU7F and STU14F, and that will involve also other students afterwards. In line 7 the teacher asks a why-question to her student (STU14F). With this question, the teacher is asking her student to advance arguments in support of the assertion she previously made in line 6 . In line 8, the student replies to the teacher by advancing an argument in support of her previous assertion. This discussion on the effects of family relationships on the adolescent development will continue involving also other students afterwards.

As far as BROAD QUESTIONS $(\mathrm{N}=65 ; 40 \%)$ are concerned, in the corpus I observed that this type of questions were typically asked by the teacher to her graduate students in the initial phase of the disciplinary discussions. Moreover, in the corpus I observed that this type of questions were in almost all cases used before of the SPECIFIC QUESTIONS, like if the teacher wanted to further specify her question and being more detailed. The following excerpt clearly illustrates this type of dynamics:

\section{Excerpt 4}

Lesson 2. Min. 24:30. Participants: teacher (TEACH), students (STU15F; STU1F). All the tables are placed in a round shape, and all students are seated at their own table. The teacher is seated together with the students. STU15F sits on the left hand side of TEACH, whilst STU1F is seated on the opposite side of STU15F.

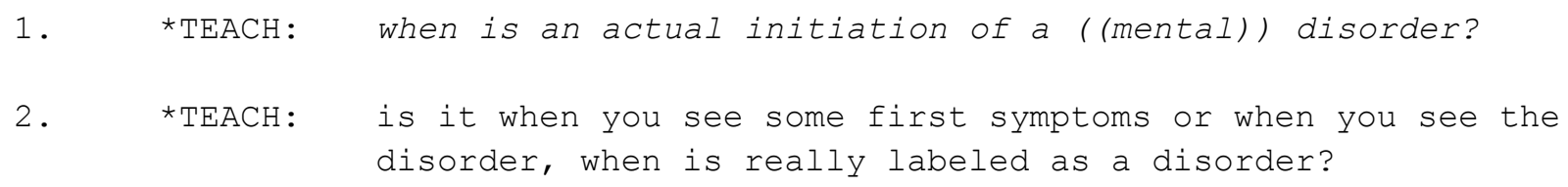


*STU15F: you need to have a predisposition, because the genes produce a predisposition to have that: : it's before the manifestation

4

it's different for disorders. even if you have a predisposition it can still go in multiple ways. I know people who were depressed and now they are not

$[\ldots]$

In example 4, the topic of the lesson is the classification of psychological disorders of adolescents according to the DSM-5, i.e., Diagnostic and Statistical Manual of Mental Disorders (APA, 2013). The sequence starts with a BROAD QUESTION asked by the teacher to her students about mental disorders in adolescence and the moment of their actual initiation (line 1, in Italic in the excerpt). The teacher does not wait for the students' replies, but she immediately asks a SPECIFIC QUESTION to their students, like if she wanted her question to be more detailed (line 2). In this case, the teacher's questions favor the beginning of an argumentative discussions initially involving two students: STU15F and STU1F. According to the first student (STU15F), the actual initiation of a mental disorder is before the manifestation, and she supports her opinion by advancing an argument (line 3). On the other hand, the second student (STU1F) claims that having a predisposition is fundamental only for certain mental disorders, not for all of them, since it can still go in multiple ways. In particular, she supports this claim by advancing argument that is based on her own personal experience (line 4). This discussion will continue for several turns, involving other students as well as the teacher.

\section{Discussion}

Since students are able to participate in argumentative debates - as amply discussed in Section 2 teachers cannot only explain the theories, laws and models, but they have also to focus on 'how scientists know' what they know by providing opportunities for students to practice participating in argumentative disciplinary discussions. As a result, students will have a chance to learn from (e.g., important theories, laws, models, or concepts) and about (e.g., how scientific argumentation is different from everyday forms of verbal conflicts) argumentation. In order to provide a further contribution to the study of argumentative practices in the learning contexts, this study set out to investigate the teacher's questions to their students during argumentative disciplinary discussions in the classroom, i.e., task-related argumentative discussions concerning the discipline taught in the course, with the aim to compare the types of questions used at undergraduate and graduate level.

The results of this study indicate that both at undergraduate and graduate level it is the teacher that in most cases favors the beginning of argumentative discussions in the classroom. She does it by inviting her students to express their opinions and doubts about the theories and notions presented during the lesson. However, looking at the questions used by the teacher at undergraduate and graduate level is possible to observe some clear differences. On the one hand, with undergraduate students the teacher asked in most cases BROAD QUESTIONS ( $\mathrm{N}=87 ; 72 \%)$. On the other hand, with graduate students the teacher asked in most cases SPECIFIC QUESTIONS (N= 96; 60\%). Among the many reasons than can at different degrees explain these differences, I will focus on two aspects that I think might contribute to clarify the reasons underlying these results. 
The first reason is the actual knowledge by students of the discipline taught in the course, i.e., Developmental Psychology. Despite undergraduate and graduate students - according to their own perception - claim to have a similar knowledge in Developmental Psychology (graduate students $M=7.25$ vs. graduate students $M=6.35$ ), in line with the results obtained by previous studies (e.g., Kelly \& Takao, 2002; Means \& Voss, 1996; Osborne, 2005) the observations of the topics treated during the lessons, of the student-teacher and student to student interactions suggest that the older students had an actual knowledge of the discipline much higher than younger students, even more than what was claimed in the answers to the questionnaire. This is in line with what has been observed by For example, in the excerpt 3 we have seen that the graduate students were able to advance arguments that refer to well-specific aspects of a scientific theory, i.e., the theory of adolescent development by Steinberg and Morris, to support their own standpoints. In the corpus, the graduate students were also able to engage in argumentative discussions relating to the different theories that treat limited aspects of a certain topic discussed during the lessons. The knowledge in Developmental Psychology of the undergraduate students was more superficial compared to graduate students. In most cases, in fact, the arguments used by the undergraduate students referred to a well-known theory, however avoiding to mention the correct term of the scientific notion they refer to. For example, in the excerpt 2 we have seen how a student advanced an argument that referred to a well-known psychological theory, i.e., Kohlberg's theory of moral development, claiming that according to this theory adolescents can normally respect authority and rules. Evidently, this student was referring to the "stage four" of Kohlberg's theory of moral development, however without mentioning it correctly.

The second reason is the different institutional commitment requested to undergraduate and graduate students. In the corpus, I observed that an argumentative effort by students was principally requested at the graduate level. For example, the teacher's questions at the graduate level were typically followed by a further why-questions asked to the students, as we have seen in the excerpt 3, where one student (STU14F) was asked to advance arguments in support of her standpoint. As already observed by previous studies (Baker, 1996; Schwarz et al., 2003), the argumentative discussions in the classroom are therefore an instrument used by the teacher to promote extrathinking in the students, digging deeper into the question being addressed. Moreover, at the graduate level the teacher appeared to take for granted that the students can engage in a complex and detailed disciplinary discussion and accordingly she asked questions that refer to specific aspects of a certain theory, e.g., the theory proposed by Steinberg and Morris in relation to adolescent risk behaviours. On the contrary, the teacher's questions at undergraduate level were rather aimed at favoring a discussion around a more general topic, e.g., how the family relationships can affect the adolescent development. Considering the entire corpus, the teacher asked SPECIFIC QUESTIONS to her undergraduate students only when the students provided clear inputs of their capacity to engage in a more complex and detailed disciplinary discussion by advancing arguments that referred to the notions and theories in the field of Developmental Psychology. Only afterwards, the teacher decided if asking a SPECIFIC QUESTION and accordingly favoring a more complex and detailed discussion with and among students, or not.

How do these results relate to actual crucial questions involving learning and argumentative practices? From an argumentative perspective, this study shows how the contextualization of argumentation (van Eemeren, 2011) is fundamental in the study of learning settings. The use of argumentation theories and analytical models cannot consider the context as given: it is needed to focus the investigation on the interactions between teachers and students in the classroom in order to properly analyze the argumentative practices in the learning contexts. From a learning 
perspective, the benefit for students resides in being active participant in the argumentative process of construction of new knowledge, and not only listeners (Baker, 2009). In agreement with other scholars (Duschl \& Osborne, 2002; Erduran \& Jiménez-Aleixandre, 2007; Ford, 2008; Kuhn, 1993; Newton et al., 1999), if students are not empowered to criticize the ideas being discussed then they must accept the ideas that sound plausible and/or are held by the individual with the most clout. The literature has already demonstrated that discussing about a certain topic is more effective than only listening it (e.g., Chin \& Osborne, 2010; Nussbaum \& Sinatra, 2003; Schwarz et al., 2000; Wiley \& Voss, 1999). In the present study, we have seen that the teacher can favor argumentative disciplinary discussions by asking to students the reasons at the basis of their standpoints and creating situations in which it makes sense for students to freely engage with one another's ideas.

Even though the present study provides new insights of the argumentative interactions between students and teacher in the learning contexts of higher education, I need to address several limitations. A first limitation of this study involves the presence of a video camera in the classroom. Although it is possible that the presence of a video camera may have influenced student behavior, it is difficult to predict in which direction. For example, students may have been more focused on the task because they knew that they were being recorded or the camera could have distracted them. Informal observation, however, suggested that students in both conditions were very attentive and were highly engaged as they worked. A second limitation involves the limited number of recordings favoured a more careful analysis but did not allow certain quantifications, such as the correlation between categories. A larger database would probably permit more quantitatively reliable data for certain statistical relationships. On the other hand, careful studies of a small number of conversations in a natural setting may give rise to a more penetrating and "data-close" analysis of the argumentative dynamics between the teacher and the students and among students.

Using a natural setting does not automatically solve the problem of obtaining optimal data. No data are perfect. Nevertheless, I believe that academic lectures are a highly informative source for the study of argumentative practices in the learning contexts, and generally they are an invaluable source for the investigation of the argumentative dynamics in the classroom within an emic perspective.

\section{Notes}

1. The Eurydice Network provides information on and analyses of European education systems and policies. As from 2013 it consists of 40 national units based in all 36 countries participating in the EU's Lifelong Learning programme. It is co-ordinated and managed by the EU Education, Audiovisual and Culture Executive Agency (EACEA) in Brussels, which drafts its studies and provides a range of online resources. For more information, see http://eacea.ec.europa.eu/education/eurydice/index_en.php

2. This course provides an overview of the theories, concepts, issues, and research in the field of adolescent development. It also focuses on changes that occur within the adolescent (including changes related to biological, socio-emotional, cognitive and moral development) as well as changes in the social context (including changes in family and peer relations, school and the larger society) using a lifespan perspective.

3. This course provides an overview of the theories, concepts, issues, and research in the fields of human development and developmental psychopathology. It also traces how the field of developmental psychopathology emerged out of the need to consider child and adolescent disorders from a developmental perspective.

4. The CHAT system provides a standardized format for producing computerized transcripts of face-to-face conversational interactions for the Child Language Data Exchange System (CHILDES). The system provides options for basic discourse transcription as well as detailed phonological and morphological analyses. Verbal 
utterances and nonverbal expressions with a clear communicative function relevant to the meal activity were identified in the transcription.

5. Standpoint is the analytical term used to indicate the position taken by a party in a discussion on an issue. As Rigotti and Greco Morasso (2009, p. 44) put it: "a standpoint is a statement (simple or complex) for whose acceptance by the addressee the arguer intends to argue".

\section{References}

Alexander, P. A., Kulikowich, J. M., \& Schulze, S. K. (1994). The influence of topic knowledge, domain knowledge, and interest on the comprehension of scientific exposition. Learning and Individual Differences, 6(4), 379-397.

Alexopoulou, E., \& Driver, R. (1996). Small-group discussion in physics: peer interaction modes in pairs and fours. Journal of Research in Science Teaching, 33(10), 1099-1114.

Anderson, R. C., Chinn, C. A., Chang, J., Waggoner, M., \& Yi, H. (1997). On the logical integrity of children's arguments. Cognition and Instruction, 15(2), 135-167.

Andrews, R. (2009). A case study of argumentation at undergraduate level in History. Argumentation. Special Issue on Argumentation and Education: Studies from England and Scandinavia, 23(4), 547-548.

APA. (2009). Publication manual of the American Psychological Association (6th ed.). Washington, DC: American Psychological Association.

APA. (2013). Diagnostic and statistical manual of mental disorders (5th ed.). Washington, DC: American Psychological Association.

Baker, M.J. (2002). Argumentative interactions, discursive operations and learning to model in science. In P. Brna, M. Baker, K. Stenning, \& A. Tiberghien (Eds.), The role of communication in learning to model (pp. 303-324). Mahwah, NJ: Lawrence Erlbaum.

Baker, M.J. (2009). Argumentative interactions and the social construction of knowledge. In N. M. Mirza, \& A.-N. Perret-Clermont (Eds.), Argumentation and Education (pp. 127-144). New York: Springer.

Bell, P., \& Linn, M. (2000). Scientific arguments as learning artifacts: designing for learning on the Web with KIE. International Journal of Science Education, 22(8), 797-817.

Bova, A., Arcidiacono, F. (2014). "You must eat the salad because it is nutritious". Argumentative strategies adopted by parents and children in food-related discussions at mealtimes. Appetite, 73(1), 81-94.

Bova, A., \& Arcidiacono, F. (2015). Beyond conflicts. Origin and types of issues leading to argumentative discussions during family mealtimes. Journal of Language Aggression and Conflict, 3(2).

Buty, C., \& Plantin, C. (2008). Argumenter en classe de sciences. Du débat a l'apprentissage. Lyon: INRP. 
Chin, C., \& Osborne, J. (2010). Supporting argumentation through students' questions: Case studies in science classrooms. Journal of the Learning Sciences, 19(2), 230-284.

Dolz, J. (1996). Learning argumentative capacities. A study of the effects of a systematic and intensive teaching of argumentative discourse in 11-12 year old children. Argumentation, $10(2), 227-251$.

Driver, R., Asoko, H., Leach, J., Mortimer, E., \& Scott, P. (1994). Constructing scientific knowledge in the classroom. Educational Researcher, 23(7), 5-12.

Driver, R., P. Newton, \& Osborne, J. (2000). Establishing the norms of scientific argumentation in classrooms. Science Education, 84(3), 287-312.

Duschl, R., \& Osborne, J. (2002). Supporting and promoting argumentation discourse in science education. Studies in Science Education, 38(1), 39-72.

Duschl, R., Schweingruber, H., \& Shouse, A., (2007). Taking science to school: Learning and teaching science in grades $K-8$. Washington, DC : National Academies Press.

van Eemeren, F. H. (2011). In context. Giving contextualization its rightful place in the study of argumentation. Argumentation, 25(2), 141-161.

van Eemeren, F. H., \& Grootendorst, R. (2004). A systematic theory of argumentation: The pragma-dialectical approach. Cambridge: Cambridge University Press.

Erduran, S., \& Jiménez-Aleixandre, M. P. (2007). Argumentation in science education: Perspectives from classroom-based research. Dordrecht: Springer.

Eurydice. (2011). Science education in Europe: National policies, practices and research. Brussels: EACEA.

Ford, M. (2008). Disciplinary authority and accountability in scientific practice and learning. Science Education, 92(3), 404-423.

Garcia-Mila, M., \& Andersen, C. (2007). Cognitive foundations of learning argumentation. In S. Erduran, \& M. P. Jiménez-Aleixandre (Eds.), Argumentation in science education: Perspectives from classroom-based research (pp. 28-44). Dordrecht: Springer.

Hatano, G., \& Inagaki, K. (2003). When is conceptual change intended? A cognitive-sociocultural view. In G.M. Sinatra, \& P.R. Pintrich (Eds.), Intentional conceptual change (pp. 407-427). Mahwah, NJ: Lawrence Erlbaum Associates.

Hogan, K., \& Maglienti, M. (2001). Comparing the epistemological underpinnings of students and scientists reasoning about conclusions. Journal of Research in Science Teaching, 38(6), 663687.

Jackson, S. (2002). Designing argumentation protocols for the classroom. In F.H. van Eemeren (Ed.), Advances in pragma-dialectics (pp. 105-120). Amsterdam: Sic Sat.

Jiménez-Aleixandre, M. P. (2007). Designing argumentation learning environments. In S. Erduran, \& M. P. Jiménez-Aleixandre (Eds.), Argumentation in science education: Perspectives from classroom-based research (pp. 89-113). Dordrecht: Springer. 
Jiménez-Aleixandre, M. P., Rodriguez, A. B., \& Duschl, R. A. (2000). “'Doing the lesson' or “'Doing science': Argument in high school genetics. Science Education, 84(6), 757-792.

Kelly, G. J., \& Chen, C. (1999). The sound of music: Constructing science as sociocultural practices through oral and written discourse. Journal of Research in Science Teaching, 36(8), 883-915.

Kelly, G., \& Takao, A. (2002). Epistemic levels in argument: An analysis of university oceanography students' use of evidence in writing. Science Education, 86(3), 314-342.

Kohlberg, L. (1984). The Psychology of Moral Development: Moral Stages and the Idea of Justice. San Francisco, CA: Harper \& Row.

Kuhn, D. (1991). The skills of argument. New York, NY: Cambridge University Press.

Kuhn, D. (1993). Science as argument: implications for teaching and learning scientific thinking. Science Education, 77(3), 319-337.

Kuhn, D., \& Udell, W. (2003). The development of argument skills. Child Development, 74(5), 1245-1260.

Macagno, F., \& Konstantinidou, A. (2013). What students' arguments can tell us: Using argumentation schemes in science education. Argumentation, 27(3), 225-243.

MacWhinney, B. (2000). The child project: Computational tools for analyzing talk. Pittsburgh, PA: Routledge.

Mason, L. (1996). Collaborative reasoning on self-generated analogies. Conceptual growth in understanding scientific phenomena. Educational Research and Evaluation, 2(4), 309-350.

Mason, L. (2001). Introducing talk and writing for conceptual change: a classroom study. Learning and Instruction, 11(6), 305-329.

McNeill, K. L., \& Krajcik, J. (2009). Synergy between teacher practices and curricular scaffolds to support students in using domain specific and domain general knowledge in writing arguments to explain phenomena. Journal of the Learning Sciences, 18(3), 416-460.

Means, M.L., \& Voss, J.F. (1996). Who reason well? Two studies of informal reasoning among children of different grade, ability, and knowledge levels. Cognition and Instruction, 14(2), 139-178.

Mortimer, E.F., \& Scott, P.H. (2003). Meaning making in secondary science classrooms. Maidenhead: Open University Press.

Muller Mirza, N., \& Perret-Clermont, A.-N. (Eds.) (2009). Argumentation and education. New York, NY: Springer.

Muller Mirza, N., \& Perret-Clermont, A.-N., Tartas, V., \& Iannaccone, A. (2009). Psychosocial processes in argumentation. In N. Muller Mirza, \& A.-N. Perret-Clermont (Eds.), Argumentation and education (pp. 67-90). New York, NY: Springer.

Nestlog, E. B. (2009). Witten argumentation by a 10-year-old pupil in Sweden. Argumentation, 23(4), 437-449. 
Newton, P., Driver, R., \& Osborne, J. (1999). The place of argument in the pedagogy of school science. International Journal of Science Education, 21(5), 553-576.

Nussbaum, E. M., \& Sinatra, G. M. (2003). Argument and conceptual engagement. Contemporary Educational Psychology, 28(3), 384-395.

Nussbaum, E. M., \& Schraw, G. (2007). Promoting argument-counterargument integration in students' writing. The Journal of Experimental Education, 76(1), 59-92.

Osborne, J. (2005). The role of argument in science education. In K. Boersma, M. Goedhart, O. de Jong, \& H. Eijkelhof (Eds.), Research and the Quality of Science Education (pp. 367-380). Dordrecht: Springer.

Osborne, J., Erduran, S., Simon, S., \& Monk, M. (2001). Enhancing the quality of argument in school science. School Science Review, 82(301), 63-70.

Pontecorvo, C., \& Girardet, H. (1993). Arguing and reasoning in understanding historical topics. Cognition and Instruction, 11(3-4), 211-227.

Rigotti, E., \& Greco Morasso, S. (2009). Editorial \& guest editors' introduction: Argumentative processes and communication contexts. Studies in Communication Sciences, 9(2), 5-18.

Sadler, T. D. (2006). Promoting discourse and argumentation in science teacher education. Journal of Science Teacher Education, 17(4), 323-346.

Sampson, V., \& Clark, D. (2008). Assessment of the ways students generate arguments in science education: Current perspectives and recommendations for future directions. Science Education, 92(3), 447-472.

Sandoval, W. A., \& Reiser, B. J. (2004). Explanation-driven inquiry: Integrating conceptual and epistemic scaffolds for scientific inquiry. Science Education, 88(3), 345-372.

Schwarz, B. B. (2009). Argumentation and learning. In N. Muller Mirza \& A.-N. Perret-Clermont (Eds.), Argumentation and education (pp. 91-126). New York, NY: Springer.

Schwarz, B. B., \& Glassner, A. (2003). The blind and the paralytic: Supporting argumentation in everyday and scientific issues. In J. Andriessen, M. Baker, \& D. Suthers (Eds.), Arguing to learn: Confronting cognitions in computer-supported collaborative learning environments (pp. 227-260). Utrecht: Kluwer Academic Publishers.

Schwarz, B. B., \& Linchevski, L. (2007). The role of task design and argumentation in cognitive development during peer interaction: The case of proportional reasoning. Learning and Instruction, 17(5), 310-331.

Schwarz, B. B., Neuman, Y., \& Biezuner, S. (2000). Two wrongs may make a right...if they argue! Cognition and Instruction, 18(4), 461-494.

Schwarz, B.B., Neuman, Y., Gil, J., \& Ilya, M. (2003). Construction of collective and individual knowledge in argumentative activity. Journal of the Learning Sciences, 12(2), 219-256. 
Simon, S., Erduran, S., \& Osborne, J. (2006). Learning to teach argumentation: Research and development in the science classroom. International Journal of Science Education, 28(2), 235-260.

Stein, N., \& Miller, C. (1993). The development of memory and reasoning skill in argumentative contexts: Evaluating, explaining, and generating evidence. In R. Glaser (Ed.), Advances in instructional psychology (pp. 285-335). Hillsdale, NJ: Lawrence Erlbaum Associates.

Steinberg L, \& Morris A.S. (2001). Adolescent development. Annual Review of Psychology, 52, 83110.

Voss, J. F., \& Van Dyke, J. A. (2001). Argumentation in psychology: Background comments. Discourse Processes, 32(2-3), 89-111.

Wiley, J., \& Voss, J. F. (1999). Constructing arguments from multiple sources: tasks that promote understanding and not just memory for text. Journal of Educational Psychology, 91(2), 301311.

Zohar, A., \& Nemet, F. (2002). Fostering students' knowledge and argumentation skills through dilemmas in human genetics. Journal of Research in Science Teaching, 39(1), 35-62. 


\section{Appendix A}

\section{Teacher-student dialogue in the academic context}

This project will investigate dialogues between students and professors during university lessons. The dialogues will be video and audio recorded. The recordings will, in first instance, be transcribed and analyzed. These recordings will not be shown to the general public.

Below are few questions. Please fill in the appropriate square for questions 1-7. Please DO NOT WRITE YOUR NAME ON THE QUESTIONNAIRE AS THIS STUDY IS ANONYMOUS. Do not feel obligated to answer all questions if you are uncomfortable or unable to do so. Thank you very much for taking the time to complete the present questionnaire, your effort is greatly appreciated.

Please contact me if you require further information about the project, or to have any questions answered. Thank you for taking the time to read this information.

Your with best wishes,

$\operatorname{Xxxxxxxx} \operatorname{Xxxxxxxx}$

Date: $\quad$ December 10, 2013

Telephone: 030 25X XX XX

E-mail: $\quad$ X. Xxxx@xx.xx

Please answer the following questions:

1. Are you a girl or a boy?

Girl $\quad \square \quad$ Boy

2. When were you born?
a) Month
b) Year

January

1985

February

1986

March

April

May

1989 
June

July

August

September

October

November

December
1990

1991

1992

1993

1994

1995

Other $19 \ldots$.

3. Where were you born?

The Netherlands

Other ....

4. What is your first language?
English
Non-English

5. Rate your ability to communicate in English

$$
\begin{array}{lllllllllll}
\text { None } & 1 & 2 & 3 & 4 & 5 & 6 & 7 & 8 & 9 & \text { Excellent }
\end{array}
$$

6. In your previous study experience, did you already take an academic course in developmental psychology?

$$
\text { Yes } \square \quad \text { No }
$$

7. Rate your knowledge in developmental psychology before the beginning of this course $\begin{array}{lllllllllll}\text { None } & 1 & 2 & 3 & 4 & 5 & 6 & 7 & 8 & 9 & \text { Excellent }\end{array}$ 


\section{Appendix B}

The transcript adopts CHAT in using the following conventions:

* indicates the speaker's turn

[...] not-transcribed segment of talking

(( )) segments added by the transcriber in order to clarify some elements of the situation

[=! ] segments added by the transcriber to indicate some paralinguistic features

$\mathrm{xxx}$ inaudible utterance(s)

\%act: description of speaker's actions

\%sit: description of the situation/setting

Several deviations from CHAT are introduced. First, punctuation symbols are used to indicate intonation contours:

\begin{tabular}{ll}
, & continuing intonation \\
$:$ & falling intonation \\
$?$ & prolonging of sounds \\
$!$ & rising intonation \\
\hline & exclamatory intonation
\end{tabular}

Second, additional symbols are added:

$\rightarrow \quad$ maintaining the turn of talking by the speaker

\%pau: $\quad$ pause of $2.5 \mathrm{sec}$

@ End end of the family meal 


\section{Favoring argumentative discussions in the classroom. A study of teacher's questions at undergraduate and graduate level}

\section{Tables}

\begin{tabular}{|l|c|c|}
\hline & Bachelor & Master \\
\hline $\begin{array}{l}\text { Students' own perception of their ability to communicate in } \\
\text { English - in a scale from 1 (none) to 9 (excellent) }\end{array}$ & 8.28 & 7.56 \\
\hline Students who already took a course in Developmental Psychology & $\begin{array}{c}\text { Yes N }=12 \\
\text { No N =2 }\end{array}$ & $\begin{array}{c}\text { Yes N }=15 \\
\text { No N }=1\end{array}$ \\
\hline $\begin{array}{l}\text { Students' own perception of their knowledge in Developmental } \\
\text { Psychology before the beginning of the course - in a scale from 1 } \\
\text { (none) to 9 (excellent) }\end{array}$ & 6.35 & 7.25 \\
\hline
\end{tabular}

Table 1. Information obtained from the questionnaire administered to bachelor and master students

\begin{tabular}{|l|c|c|c|}
\hline & Bachelor & Master & TOTAL \\
\hline Number of argumentative discussions & 35 & 167 & 242 \\
\hline Arguments put forth by students & 75 & 3.88 & 3.66 \\
\hline $\begin{array}{l}\text { Average number of arguments advanced during an } \\
\text { argumentative discussion }\end{array}$ & 3.26 & 161 & 272 \\
\hline $\begin{array}{l}\text { Teacher's questions to their students during the } \\
\text { argumentative disciplinary discussions in the classroom }\end{array}$ & 121 & 2.72 & 2.89 \\
\hline $\begin{array}{l}\text { Average number of teacher's questions to their students } \\
\text { during the argumentative disciplinary discussions in the } \\
\text { classroom }\end{array}$ & 3.45 & $65(40 \%)$ & 121 \\
\hline $\begin{array}{l}\text { Teacher's BROAD questions to their students during the } \\
\text { argumentative disciplinary discussions in the classroom }\end{array}$ & $87(72 \%)$ & $96(60 \%)$ & 161 \\
\hline $\begin{array}{l}\text { Teacher's SPECIFIC questions to their students during } \\
\text { the argumentative disciplinary discussions in the } \\
\text { classroom }\end{array}$ & $34(28 \%)$ & & \\
\hline
\end{tabular}

Table 2. Contributions of students and teacher in argumentative discussions in the classroom 